\title{
Correction to: Neurohistology and Imaging Techniques
}

\section{Radek Pelc, Wolfgang Walz, and J. Ronald Doucette}

\section{Correction to:}

Radek Pelc et al. (eds.), Neurohistology and Imaging Techniques, Neuromethods, vol. 153, https://doi.org/10.1007/978-1-0716-0428-1

In the online version of this book, the book editor's name was inadvertently misspelled throughout the book and Chapters 08, 09, and 13 were published inadvertently with missing details: affiliation for authors (Chapters 08, 09, and 13), missing e-mail address (Chapter 13), and Corresponding Author not identified (Chapter 13).

The errors listed above were corrected and the revised book is available online.

\footnotetext{
The updated version of the book can be found at https://doi.org/10.1007/978-1-0716-0428-1 https://doi.org/10.1007/978-1-0716-0428-1_8 https://doi.org/10.1007/978-1-0716-0428-1_9 https://doi.org/10.1007/978-1-0716-0428-1_13
} 